\title{
Possible Role of Trichothecene Mycotoxins in Virulence of Fusarium graminearum on Maize
}

L. J. Harris, Eastern Cereal and Oilseed Research Centre, Agriculture and Agri-Food Canada, Ottawa, Ontario K1A 0C6 Canada; A. E. Desjardins and R. D. Plattner, Mycotoxin Research, National Center for Agricultural Utilization Research, USDA/ARS, Peoria, IL 61604; P. Nicholson, John Innes Centre, Norwich Research Park, Colney, Norwich NR4 7UH, UK; G. Butler and J. C. Young, Eastern Cereal and Oilseed Research Centre, Agriculture and Agri-Food Canada, Ottawa, Ontario K1A 0C6 Canada; G. Weston, John Innes Centre, Norwich Research Park, Colney, Norwich NR4 7UH, UK; R. H. Proctor and T. M. Hohn, Mycotoxin Research, National Center for Agricultural Utilization Research, USDA/ARS, Peoria, IL 61604

\begin{abstract}
Harris, L. J., Desjardins, A. E., Plattner, R. D., Nicholson, P., Butler, G., Young, J. C., Weston, G., Proctor, R. H., and Hohn, T. M. 1999. Possible role of trichothecene mycotoxins in virulence of Fusarium graminearum on maize. Plant Dis. 83:954-960.

Trichothecene-producing and -nonproducing Fusarium graminearum strains were tested for their ability to cause Gibberella ear rot in field trials at two locations-Ottawa, Ontario, and Peoria, Illinois-in 1996. Maize ears were inoculated with wild-type or transgenic $F$. graminearum strains in which the trichothecene biosynthetic pathway had been disabled by the specific disruption of the trichodiene synthase gene and with a derivative revertant strain in which trichothecene production had been restored through recombination. A silk channel inoculation method was employed at both locations. In addition, a kernel puncture inoculation method was used at the Ontario location. Harvested maize ears were analyzed for visual disease severity, grain yield, deoxynivalenol (DON) concentration, and fungal biomass by quantitative polymerase chain reaction (PCR) and/or ergosterol quantitation. There was a significant correlation $(r=0.86)$ between data obtained from the two different methods of quantifying fungal biomass. The trichothecene-nonproducing strains were still pathogenic but appeared less virulent on maize than the trichothecene-producing progenitor and revertant strains, as assayed by most parameters. This suggests that the trichothecenes may act as virulence factors to enhance the spread of $F$. graminearum on maize.
\end{abstract}

Globally, Fusarium graminearum (sexual stage Gibberella zeae) is an important plant pathogen that attacks a wide range of plant species, including many important crop plants such as maize (Zea mays) (ear and stalk rot), wheat, and barley (head blight). F. graminearum infection reduces both yield and quality of the grain. The reduction in quality is partially a result of mycotoxins produced by this fungus. Maize ears infected with $F$. graminearum (Gibberella ear rot) have been shown to contain the trichothecenes deoxynivalenol (DON), 15-acetyldeoxynivalenol (15AcDON),

Corresponding author: L. J. Harris

E-mail: harrislj@em.agr.ca

Current address of T. M. Hohn: Seeds Biotechnology Research Unit, 3054 Cornwallis Road, Novartis Seeds, Research Triangle Park, NC 27709.

ECORC Contribution 991400.

Accepted for publication 28 June 1999.

Publication no. D-1999-0809-01R

This article is in the public domain and not copyrightable. It may be freely reprinted with customary crediting of the source. The American Phytopathological Society, 1999. and 3-acetyldeoxynivalenol (3AcDON), as well as zearalenone $(1,16,17)$ and fusarin $\mathrm{C}$ (7).

Gibberella ear rot of maize is characterized by a pinkish to reddish colored mold on the kernels as well as on the cob and husk tissues. Colonization can occur over 8 weeks or more in the field, and growth may continue in storage under certain conditions. Major sources of inoculum are ascospores or macroconidia produced on overwintered plant debris on the soil surface (30). Natural infection occurs through one of two routes. Spores may land on maize silks (just after silking and before silks begin to senesce) and, under favorable conditions (high humidity and warm temperatures), mycelia grow down the silk channel toward the developing kernels, which are subsequently infected $(23,30)$. Damage to the ear by birds or insects may also predispose the kernels to infection by providing an entry point $(30,31)$. These two routes of entry are the basis for evaluating resistance using both a silk channel and a kernel wounding inoculation proto$\operatorname{col}(21,22)$.

The mycotoxin DON (also named vomitoxin) was first detected in wheat infected with $F$. graminearum in 1981 . Due to the toxicity of DON and other trichothecene mycotoxins, Canadian safety threshold values have been recommended for DON mycotoxin contamination in grain used for human food and animal feed (33). The United States Food and Drug Administration has a guideline of $1 \mu \mathrm{g} / \mathrm{g}$ for finished flour products (14).

Trichothecenes are a large family of sesquiterpene epoxides, whose chemical structures vary in the position and number of hydroxylations, as well as in the position, number, and complexity of esterifications (25). The biosynthesis of trichothecenes in Fusarium proceeds from trichodiene, the first intermediate unique to the trichothecene pathway $(3,36)$. The enzyme trichodiene synthase catalyzes the cyclization of farnesyl pyrophosphate to trichodiene (11). The trichodiene synthase gene, TRI5, has been cloned from $F$. sporotrichioides (9), $F$. sambucinum (10), and $F$. graminearum (20). Southern genomic analysis indicates that TRI5 is present as a single copy in the genomes of these Fusarium species. As trichodiene synthase catalyzes the first unique step in the pathway and is present as a single copy in this haploid fungus, $F$. graminearum mutants lacking a functional trichodiene synthase gene are unable to produce trichothecenes.

Trichothecenes are potent phytotoxins and are produced by many plant-pathogenic Fusarium species (13). Accordingly, trichothecenes may play a role in pathogenicity. Virulence is a component of pathogenicity and can be defined as the relative ability of a pathogen to cause damage on a host. The role of trichothecenes has been investigated in a number of Fusarium diseases of crop plants (4). Molecular gene disruption of TRI5 led to the isolation of Fusarium mutants deficient in the production of trichothecenes. Field trials conducted by the USDA and Purdue University have demonstrated that trichothecene-nonproducing strains of $F$. graminearum are less virulent on wheat (6). Analysis of similar trichothecene-nonproducing mutants of $F$. sambucinum indicated that trichothecene production increased the virulence of $F$. sambucinum on parsnip roots but did not affect virulence on potato 
tubers (5). These results demonstrated that the importance of trichothecene production as a virulence factor varies depending on the host. Therefore, although trichothecene production is important for virulence of $F$. graminearum on wheat, it cannot be assumed that trichothecenes contribute to virulence on maize. The objective of this study was to inoculate maize ears with either trichothecene-producing $\left(T R I 5^{+}\right)$or -nonproducing $\left(T R I 5^{-}\right)$strains of $F$. graminearum to assess the role of trichothecenes in Gibberella ear rot.

\section{MATERIALS AND METHODS}

Fungal strains and growth. The $F$. graminearum trichothecene-producing $\left(T R I 5^{+}\right)$ strain GZ3639 $\left(\mathrm{Wt}^{\mathrm{US}}\right)$ was isolated from scabby wheat in Kansas (2) and was the progenitor wild-type strain of all the transgenic strains produced. The generation of trichothecene-nonproducing $\left(T R I 5^{-}\right)$ strains GZT33 (M1) and GZT40 (M2), and trichothecene-producing revertant GZT106 (R) was previously described $(6,20)$. DAOM180378 $\left(\mathrm{Wt}^{\mathrm{CA}}\right)$ is a wild-type isolate originally collected from naturally infected maize ears and was acquired from the Canadian Collection of Fungus Cultures, Agriculture and Agri-Food Canada, Ottawa, Ontario.

Macroconidial suspensions of all $F$. graminearum strains were prepared using one of two methods. For the Ontario site, inoculum was grown using a modified form of Bilay's liquid medium (2 $\mathrm{g}$ of $\mathrm{KH}_{2} \mathrm{PO}_{4}, 2 \mathrm{~g}$ of $\mathrm{KNO}_{3}, 1 \mathrm{~g}$ of $\mathrm{MgSO}_{4}, 1 \mathrm{~g}$ of $\mathrm{KCl}, 1 \mathrm{~g}$ of dextrose, $0.2 \mathrm{mg}$ of $\mathrm{FeCl}_{3}$, $0.2 \mathrm{mg}$ of $\mathrm{MnSO}_{4}, 0.2 \mathrm{mg}$ of $\mathrm{FeSO}_{4}$, and $0.2 \mathrm{mg}$ of $\mathrm{ZnSO}_{4}$ in 1 liter of water). Plugs $\left(1 \mathrm{~cm}^{2}\right)$ from two V8 agar culture plates (32) with confluent $F$. graminearum cultures were added to 1.2 liters of autoclaved medium in 2.8-liter flasks and aerated aseptically for 7 days (14 h fluorescentincandescent light at $25^{\circ} \mathrm{C}$ and $10 \mathrm{~h}$ dark at $20^{\circ} \mathrm{C}$ ). For the Illinois site, cultures were grown on V8 agar plates, and spores (macroconidia) were washed from cultures grown for 7 to 10 days ( $12 \mathrm{~h}$ black-fluorescent light at $25^{\circ} \mathrm{C}$ and $12 \mathrm{~h}$ dark at $20^{\circ} \mathrm{C}$ ). Spore concentrations were typically 1 to $2 \times 10^{6}$ per $\mathrm{ml}$, and cultures were diluted to $5 \times 10^{5}$ spores per $\mathrm{ml}$ with distilled water (Ontario site) or $50 \%$ Bilay's liquid medium (Illinois site) on the day of inoculation.

Field inoculation. The field trial was held at two sites in 1996: in Ottawa, Ontario, and Peoria, Illinois. At both sites, two susceptible public maize inbreds, CO354 and CO359, were inoculated using the silk channel inoculation technique with two wild-type trichothecene-producing $\left(\right.$ TRI5 $\left.^{+}\right) \quad \mathrm{Wt}^{\mathrm{US}} \quad(\mathrm{GZ3639})$ and $\mathrm{Wt}^{\mathrm{CA}}$ (DAOM180378) strains, two transgenic trichothecene-nonproducing $\left(T R I 5^{-}\right) \mathrm{M} 1$ (GZT33) and M2 (GZT40) mutants, one transgenic trichothecene-producing $\left(T R I 5^{+}\right)$ revertant R (GZT106), and a water control.
A subset of treatments $\left(\mathrm{Wt}^{\mathrm{US}}, \mathrm{Wt}^{\mathrm{CA}}, \mathrm{M} 2\right.$, and water) was also inoculated using the kernel inoculation technique at the Ontario site.

The silk channel and kernel inoculation experiments were designed as four replicate split plots at the Ontario test site with one of two inbreds assigned to each whole plot and the inoculation treatments randomly assigned to the subplots. The silk inoculation field experiment was carried out in Illinois with the two inbreds planted as separate experiments. Each experiment was analyzed as a completely randomized design.

The silk channel inoculation technique involved the injection of a 2-ml macroconidial suspension into the silk channel (inside the husk cavity and above the cob) of the primary ear 4 to 7 days post-silk emergence. At the Ontario site, this was accomplished using an 18 gauge stainless steel hypodermic needle attached to a graduated automatic vaccinator with a backpack (Nasco Co., Fort Atkinson, WI) (21). At the Illinois site, inoculations were carried out using a disposable $10-\mathrm{ml}$ syringe and 18 gauge hypodermic needle. Kernel inoculation was also performed at the Ontario test site. A custom-made selfrefilling graduated kernel inoculator has four hollow stainless steel pins through which $0.4 \mathrm{ml}$ of spore suspension can be pumped into a group of four pierced kernels (22).

Harvest and evaluation. All ears were harvested 5 to 6 weeks postinoculation from the Ontario site and 6 to 7 weeks postinoculation from the Illinois site and brought into a contained environment chamber for husking and evaluation. We used a rating scale based on a visual estimation of the percentage of visibly infected kernels on an ear as follows: $1=$ $0 \%, 2=1$ to $3 \%, 3=4$ to $10 \%, 4=11$ to $25 \%, 5=26$ to $50 \%, 6=51$ to $75 \%, 7=76$ to $100 \%$ (23). After drying, all ears were hand-shelled and kernels from ears of the same plot-row were weighed and bulked. Each kernel sample was mixed thoroughly to promote a random distribution of kernels. At the Ontario site, a 50-g sample was ground to a fine powder in a Retsch ultra centrifugal mill type ZM1 (Brinkman Instruments, Inc., Rexdale, Ontario) with a $0.5-\mathrm{mm}$ mesh screen. At the Illinois site, a 300 -g sample of kernels was dried at 45 to $50^{\circ} \mathrm{C}$ for 2 to 3 days. The dried sample was ground in a Stein Laboratory Mill (Model M-2, The Steinlite Corp., Atchison, KS).

Identification of fungal strains. Simultaneously with the visual disease symptom assessment, kernels were collected from the leading edge of the infection for strain identification. One kernel from each ear was surface-disinfected with $0.5 \%$ sodium hypochlorite (Illinois site) or with $70 \%$ ethanol followed by $1.6 \%$ sodium hypochlorite (Ottawa site) and cultured on a Fusarium-selective Nash-Sny- der medium (18). Fusarium-like colonies were transferred to potato dextrose agar to facilitate identification (18). Putative $F$. graminearum isolates were subcultured to individual plates of V8 juice agar medium (32). Mycelium harvested from these plates was lyophilized, and DNA was extracted as described (6). Polymerase chain reactions $(\mathrm{PCR})$ used primer pairs capable of specifically identifying wild-type and transgenic fungal strains to amplify sequences from the isolated template DNA. The PCR product band pattern from each field isolate was compared with those from wild-type and transgenic strains to determine the genotype of each field isolate.

DON analysis. The concentration of DON from the Ottawa test site was determined by competitive direct enzyme-linked immunosorbent assay (CD-ELISA) using purified monoclonal antibodies against DON, as described by Sinha and Savard (26), with slight modifications (27). Duplicate samples were prepared for analysis by adding $5 \mathrm{ml}$ of methanol:water (1:9) to $1 \mathrm{~g}$ of ground kernels and shaking for $1 \mathrm{~h}$ at room temperature. The samples were centrifuged at 2,000 rpm for $5 \mathrm{~min}$, passed through a $0.22-\mu \mathrm{m}$ filter, and stored at $4{ }^{\circ} \mathrm{C}$ until assayed.

DON quantitation at the Illinois test site was by GC/MS. A 25-g subsample of the ground maize was extracted with $100 \mathrm{ml}$ of 86:14 acetonitrile:water by shaking for $1 \mathrm{~h}$ and filtered through Whatman $2 \mathrm{v}$ filter paper. DON standards were prepared at $100,300,600$, and $1,000 \mathrm{pg} / \mu \mathrm{l}$ in $86: 14$ acetonitrile:water. Standard solution (100 $\mu \mathrm{l})$ was added to a vial containing $40 \mu \mathrm{l}$ of maize extract that did not contain DON and evaporated to dryness at $60^{\circ} \mathrm{C}$ under a nitrogen stream. Then $100 \mu \mathrm{l}$ of Trisil-TBT (Pierce Chemical Co., Rockford, IL) was added, and the vials were capped and heated at $75^{\circ} \mathrm{C}$ for $20 \mathrm{~min}$. For the samples with lower levels of DON, $40 \mu \mathrm{l}$ of the extract was evaporated and derivatized the same way. The samples with higher DON levels were diluted 1:5 with $86: 14$ acetonitrile:water, and $40 \mu \mathrm{l}$ of the diluted extract was added to a vial containing $32 \mu \mathrm{l}$ of the same DON-free maize extract used to make the standards. All samples and standards were analyzed using 1- $\mu$ l injections. The analyses were performed with a Varian 3400 gas chromatograph with a $30 \mathrm{~m} \times$ $0.25 \mathrm{~mm}$ (i.d.) capillary column coated with DB-5ht at $0.1-\mu \mathrm{m}$ film thickness (J\&W Scientific, Folsom, CA). The column was connected directly to the ion source of a TSQ 700 mass spectrometer (Finnigan MAT, San Jose, CA). Helium was the carrier gas. The oven was held at $80^{\circ} \mathrm{C}$ for $1 \mathrm{~min}$, then programmed at $10^{\circ} \mathrm{C} / \mathrm{min}$ for $12 \mathrm{~min}$ and finally at $5^{\circ} \mathrm{C} / \mathrm{min}$ for $10 \mathrm{~min}$. Methane was used as the CI gas. Full negative ion mass spectra from 100 to $650 \mathrm{~m} / \mathrm{z}$ at $0.5 \mathrm{~s} / \mathrm{scan}$ were recorded. The MS (m/z [\%]) of DON was 512 (8), 297 (100), and 215 (20). Quanti- 
tation was based on the area of the m/z 297 peak. Standards were run before and after each series of eight samples, and a linear standard curve was fitted and used to determine the DON in duplicate runs of each sample, which were then averaged.

Quantitative PCR. $F$. graminearum DNA was quantified relative to total DNA using PCR primers specific to $F$. graminearum and amplifying in the presence of a known quantity of heterologous competitor fragment. DNA was extracted from milled grain from the Illinois site using a Nucleon Phytopure DNA extraction kit (Scotlab, Coatbridge, Scotland) according to the manufacturer's instructions, except that dry, milled material $(0.2$ g) was used. The material from the Canadian site was extracted using a Wizard genomic DNA purification kit (Promega, Madison, WI) according to the manufacturer's recommendations, except that each sample consisted of $0.01 \mathrm{~g}$ of milled material. DNA from all samples was quantified by SybrGreen fluorescence according to the method of Hopwood et al. (12), and subsamples were diluted to a fixed concentration (typically $4 \mathrm{ng} / \mu \mathrm{l}$ ) prior to PCR.

Competitive PCR was carried out on all maize samples to quantify the amount of DNA of $F$. graminearum present. Competitive PCR reactions were carried out using primer pair Fg16F/Fg16R (CTCCGGATATGTTGCGTCAA/GGTAGGTATCCG ACATGGCAA), as described previously (19). Each reaction contained $12 \mathrm{fg}$ of competitor template. In some samples, the level of $F$. graminearum DNA exceeded the upper limit for quantification. In these instances, the samples were diluted further to bring levels within the range of the standard curve (0.001 to $10 \mathrm{ng}$ of fungal DNA). PCR analysis of all samples was performed three times (Illinois site) or four times (Ontario site).

Following amplification, the PCR products were separated by electrophoresis through 2\% agarose gels. Gels were stained with ethidium bromide, viewed under UV light on a Gel Doc 1000 system (Bio-Rad Laboratories, Richmond, CA), and analyzed using Molecular Analyst software (Bio-Rad) to estimate the relative degree of amplification of the fungal and competitor PCR product in each sample. The amount of fungal DNA of $F$. graminearum in plant samples was estimated by relating the PCR product ratios to a standard curve, as described by Nicholson et al. (19).

Ergosterol analysis. Ergosterol quantitation was only carried out on maize inoculated at the Ontario test site. Ergosterol was extracted from duplicate 50-g samples of ground kernels from each bulked row, as described in Young (34). Samples were suspended in $2.0 \mathrm{ml}$ of methanol, placed into a $27-\mathrm{ml}$ culture tube, treated with 0.5 $\mathrm{ml}$ of $2 \mathrm{M} \mathrm{NaOH}$, and tightly sealed with a Teflon-lined screw cap. The culture tubes were tightly sealed within individual screw-capped 1-liter plastic bottles and microwaved (domestic oven at $2,450 \mathrm{MHz}$ and $750 \mathrm{~W}$ ) twice at $50 \%$ power for $20 \mathrm{~s}$. The contents were neutralized with $1 \mathrm{M}$ $\mathrm{HCl}$, treated with $2 \mathrm{ml}$ of methanol, and then extracted with pentane $(3 \times 2 \mathrm{ml})$. The combined pentane extracts were passed through a $0.45-\mu \mathrm{m}$ filter, evaporated to dryness, and resuspended in ethyl acetatepentane (1:1) prior to analysis. Total ergo-

Table 1. Mean values of disease rating, yield, deoxynivalenol (DON), and ergosterol content of silk channel-inoculated maize ears in Ontario

\begin{tabular}{|c|c|c|c|c|}
\hline Inoculation $^{\mathrm{a}}$ & $\begin{array}{l}\text { Disease } \\
\text { rating }\end{array}$ & $\begin{array}{c}\text { Yield } \\
\mathbf{k w t} / \text { ear }(\mathrm{g})\end{array}$ & $\begin{array}{c}\mathbf{L n}^{\mathrm{c}} \text { DON } \\
\text { (DON in ppm) }\end{array}$ & $\begin{array}{c}\mathbf{L n}^{\mathrm{c}}(\text { ergosterol+1) } \\
\text { (ergosterol in ppm) }\end{array}$ \\
\hline \multicolumn{5}{|l|}{ Maize inbred CO354 } \\
\hline $\mathrm{Wt}^{\mathrm{US}}$ & 6.7 & 14.5 & $7.1(1302.1)$ & $6.2(541.7)$ \\
\hline $\mathrm{R}$ & 6.7 & 17.5 & $7.0(1092.2)$ & $6.0(414.9)$ \\
\hline M1 & 4.8 & 44.8 & $-0.7(0.5)$ & $3.7(41.8)$ \\
\hline M2 & 5.7 & 32.5 & $0.2(1.4)$ & $4.8(135.0)$ \\
\hline $\mathrm{Wt}^{\mathrm{CA}}$ & 5.9 & 26.5 & $5.6(484.8)$ & $5.4(255.5)$ \\
\hline Water & 1.2 & 52.6 & $-1.7(0.8)$ & $0.5(0.7)$ \\
\hline Contrasts: $\mathrm{R}$ vs. $\mathrm{Wt}^{\mathrm{US}}$ & $P=0.844$ & $P=0.229$ & $P=0.670$ & $P=0.256$ \\
\hline M1 vs. M2 & $P<0.001$ & $P<0.001$ & $P=0.016$ & $P<0.001$ \\
\hline $\mathrm{R} \& W \mathrm{t}^{\mathrm{US}}$ vs. M's & $P<0.001$ & $P<0.001$ & $P<0.001$ & $P<0.001$ \\
\hline \multicolumn{5}{|l|}{ Maize inbred C0359 } \\
\hline $\mathrm{Wt}^{\mathrm{US}}$ & 6.1 & 36.5 & $6.0(405.0)$ & $5.2(186.2)$ \\
\hline $\mathrm{R}$ & 6.1 & 31.5 & $6.1(494.8)$ & $5.4(217.8)$ \\
\hline M1 & 5.2 & 45.3 & $-0.3(0.8)$ & $4.5(87.6)$ \\
\hline M2 & 5.2 & 46.1 & $-0.8(0.5)$ & $4.2(68.3)$ \\
\hline $\mathrm{Wt}^{\mathrm{CA}}$ & 4.4 & 45.4 & $5.0(160.3)$ & $4.5(111.2)$ \\
\hline Water & 1.6 & 61.7 & $-2.0(0.2)$ & $1.0(2.1)$ \\
\hline Contrasts: $\mathrm{R}$ vs. $\mathrm{Wt}^{\mathrm{US}}$ & $P=0.983$ & $P=0.048$ & $P=0.641$ & $P=0.495$ \\
\hline M1 vs. M2 & $P=0.961$ & $P=0.741$ & $P=0.156$ & $P=0.217$ \\
\hline $\mathrm{R} \& W t^{\mathrm{US}}$ vs. M's & $P<0.001$ & $P<0.001$ & $P<0.001$ & $P<0.001$ \\
\hline $\mathrm{SED}^{\mathrm{d}}$ & 0.2 & 2.4 & 0.3 & 0.2 \\
\hline
\end{tabular}

sterol was determined by reversed phase high-performance liquid chromatography (HPLC) with ultraviolet detection at 282 $\mathrm{nm}$. HPLC separations were achieved with a reversed phase ODS 5 column $(250 \times 4.6$ $\mathrm{mm}$ ) eluted with acetonitrile-methanol$\mathrm{H}_{2} \mathrm{O}(74: 20: 6)$ at $2 \mathrm{ml} / \mathrm{min}$. Ergosterol detection was confirmed by gas chromatography-mass spectrometry (GC/MS) using a DB5-MS capillary column $(15 \mathrm{~m})$ temperature-programmed from 150 to $300^{\circ} \mathrm{C}$ at $20^{\circ} \mathrm{C} / \mathrm{min}$. Detection and quantitation were by electron ionization MS with multiple ion monitoring $(\mathrm{m} / \mathrm{z} 337,363$, 396).

Statistical analysis. The two Ontario field tests (silk and kernel inoculation) were analyzed as split plots. In the silk inoculation experiment, the following contrasts were of interest: a comparison of the revertant strain R (GZT106) versus the wild-type $\mathrm{Wt}^{\mathrm{US}}$ (GZ3639); a comparison of the two mutants, M1 (GZT33) versus M2 (GZT40); and a comparison of the average of $\mathrm{R}$ and $\mathrm{Wt}^{\mathrm{US}}$ with the average of the mutants, M1 and M2. Mention is also made of other single degree of freedom contrasts based on pairwise $t$ tests, for example, in the kernel inoculation experiments. Because there were significant inbred by treatment interactions, the contrasts were examined separately for each inbred. In the Illinois experiment, the data for the two inbreds were analyzed as separate, completely randomized designs with the same contrasts. In the case of DON and ergosterol, the natural logarithm of the data was analyzed to stabilize variances across treatments. For data sets with zero values, the value "one" was added prior to transformation to avoid taking logarithms of zeroes (28). Means, standard errors, and significance tests are presented for DON, ergosterol, and percent fungal DNA on the transformed scale. Untransformed means have also been presented for the convenience of the reader. Correlations between variables of interest were examined. The final analyses were carried out using the SAS correlation procedure and general linear models procedure (SAS Institute, Cary, NC). Unless noted otherwise, significance levels are at the 5\% level.

Test protocol. The Animal and Plant Health Directorate of the Food Production and Inspection Branch of Agriculture \& Agri-Food Canada authorized the field test conducted in Ontario under conditions included in an addendum to Permit to Import 186736. The Illinois field test described in this report was conducted under terms outlined in permit 96-026-01R granted by the United States Department of Agriculture, Animal and Plant Health and Inspection Service.

\section{RESULTS}

Ontario test site. Both methods of inoculation were effective; $100 \%$ of ears inoculated via the kernel puncture method 
and $94 \%$ of ears inoculated through the silk channel with the wild-type $\mathrm{Wt}^{\mathrm{US}}$ strain exhibited disease symptoms over more than $25 \%$ of the ear (disease rating greater than 4) (Table 1). Figure 1 illustrates the frequency distribution of the visual disease ratings (for mean values see Table 1) assigned to individual ears that were silk channel-inoculated with strains $\mathrm{Wt}^{\mathrm{US}}, \mathrm{R}$, $\mathrm{M} 1$, and M2. Inoculation of both maize inbreds with the trichothecene-producing $\mathrm{Wt}^{\mathrm{US}}$ and $\mathrm{R}$ (revertant) strains resulted in a greater frequency of ears severely infected with Fusarium than inoculation with the trichothecene-nonproducing strains, M1 and $\mathrm{M} 2$ (Fig. 1A and $\mathrm{B}$ ). The $\mathrm{Wt}^{\mathrm{US}}$ and $\mathrm{R}$ strains each caused mean disease ratings of 6.7 on $\mathrm{CO} 354$ and 6.1 on $\mathrm{CO} 359$, and caused significantly more disease than the trichothecene-nonproducing strains $(P \leq$ 0.001) (Table 1). The mean disease rating for inbred CO359 ears inoculated with either M1 or M2 was 5.2, while the mean ratings for inbred $\mathrm{CO} 354$ ears inoculated with M1 and M2 were 4.8 and 5.7, respectively.

The trichothecene-producing and nonproducing strains exhibited very similar visual disease ratings when inoculated directly by kernel wounding. This was the result of rapid and very advanced development in most ears of the visual symptoms used to assess disease. Mean ratings at or approaching 7 (Table 2) were observed at the time of disease assessment. A disease rating of 7 encompassed a wide scope of infection, ranging from normalsized ears with fully developed kernels, albeit greater than $75 \%$ infected, to very small ears barely recognizable as maize and completely invaded by the fungus. Strain M2 was only significantly less virulent than $\mathrm{Wt}^{\mathrm{US}}$ when inoculated onto inbred CO354 $(P \leq 0.001)$, but not when inoculated onto inbred CO359 $(P=0.617)$ (Table 2).

The trichothecene-producing strains $\mathrm{Wt}^{\mathrm{US}}$ and $\mathrm{R}$ significantly decreased yield $(P \leq 0.001)$ relative to the trichothecenenonproducing M1 and M2 strains following silk inoculation (Table 1). Compared with inbred CO359, inbred CO354 showed greater differences in yield between the trichothecene-producing ( $\mathrm{Wt}^{\mathrm{US}}$ and $\left.\mathrm{R}\right)$ and the nonproducing (M1 and M2) strains. The M2 strain was associated with significantly higher yields than its wild-type progenitor $\mathrm{Wt}^{\mathrm{US}}$ on both inbreds in kernel inoculation experiments (Table 2).

DON concentrations were determined in the Ontario grain by CD-ELISA. As expected, high concentrations of DON (means from 160 to $1,302 \mathrm{ppm}$ ) were detected in maize inoculated with the trichothecene-producing strains (Tables 1 and 2). Kernels from plants inoculated with the trichothecene-nonproducing strains M1 and M2 contained DON levels slightly above background water-inoculated control levels, with means ranging from 0.5 to 2.2 ppm (Tables 1 and 2). These results indicated that the Gibberella ear rot observed in ears inoculated with M1 and M2 was caused predominantly by trichothecenenonproducing strains.

Ergosterol quantitation (a measure of total fungal biomass) was carried out on harvested seed from both silk-inoculated and kernel-inoculated ears, while quantitafrom silk-inoculated maize only. The PCR technique ascertains the proportion of $F$. graminearum DNA relative to total DNA (fungal and plant). As with the other parameters, both the ergosterol and quantitative PCR was used on the harvested seed

tive PCR methods indicated significant differences $(P \leq 0.001)$ in fungal biomass between ears inoculated with the trichothecene-producing and nonproducing strains, except on kernel-inoculated CO359 ears $(P$ $=0.052$ ) (Tables 1 and 2, Fig. 2A).

Both ergosterol quantitation and quantitative $F$. graminearum-specific PCR analyses were performed on silk-inoculated material at the Ontario site. These two analyses were carried out blindly in two separate laboratories using subsamples of the same original ground kernel samples. The coefficient of correlation between the 48 genotype by treatment by replicate

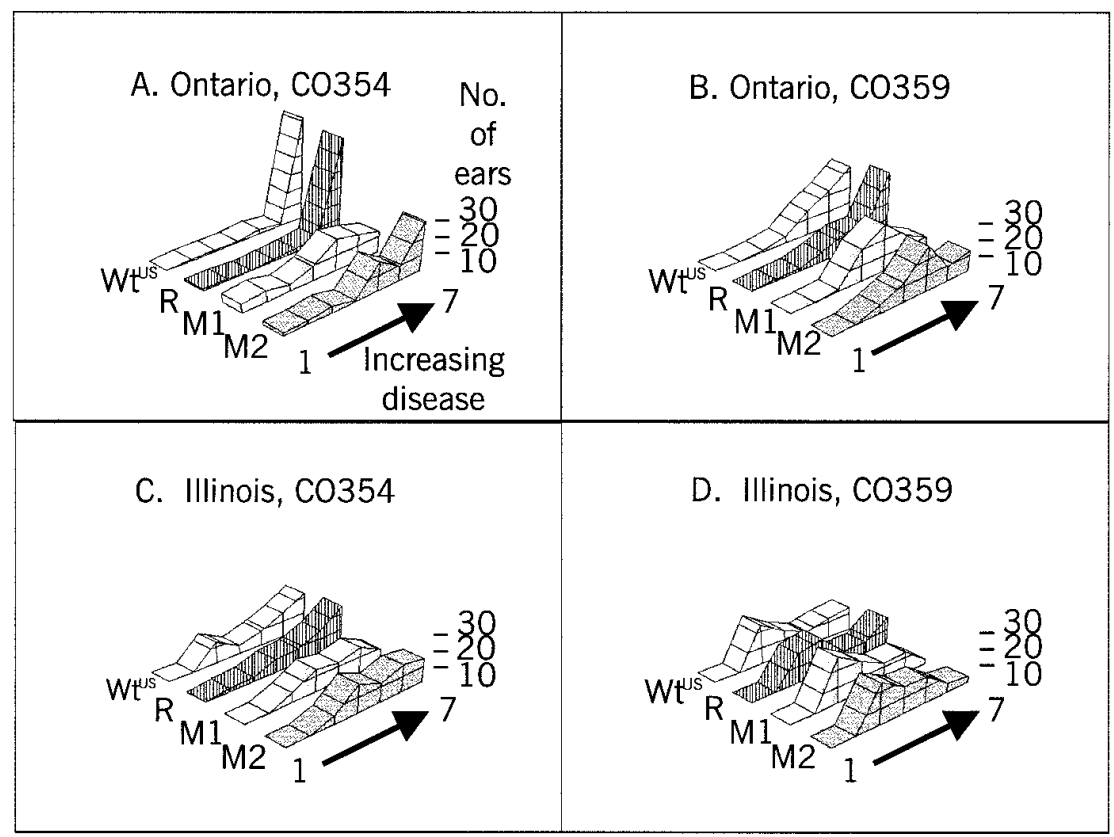

Fig. 1. Frequency distribution of visual disease ratings of inoculated ears. The y-axis of 1 to 7 represents the visual disease rating scale, ranging from no visible infection to heavily infected. Each increment on the $\mathrm{z}$-axis represents 10 ears. The inoculum represented are $\mathrm{Wt}^{\mathrm{US}}=\mathrm{GZ3639}$ (wild-type TRI5 $\left.5^{+}\right), \mathrm{R}=\mathrm{GZT} 106\left(\right.$ revertant $\left.T R I 5^{+}\right), \mathrm{M} 1=\operatorname{GZT33}\left(\right.$ TRIS $\left.^{-}\right)$, and M2 = GZT40 $\left(\right.$TRI5 $\left.^{-}\right)$.

Table 2. Mean values of disease rating, yield, deoxynivalenol (DON), and ergosterol content of kernel-inoculated maize ears in Ontario

\begin{tabular}{|c|c|c|c|c|}
\hline Inoculation $^{\mathrm{a}}$ & $\begin{array}{c}\text { Disease } \\
\text { rating }\end{array}$ & $\begin{array}{c}\text { Yield } \\
\text { kwt } / \text { ear (g) }\end{array}$ & $\begin{array}{c}\mathbf{L n}^{\mathrm{c}} \text { DON } \\
\text { (DON in ppm) }\end{array}$ & $\begin{array}{c}\operatorname{Ln}^{\mathrm{c}}(\text { ergosterol+1) } \\
(\text { ergosterol in ppm) }\end{array}$ \\
\hline \multicolumn{5}{|l|}{ Maize inbred CO354 } \\
\hline $\mathrm{Wt}^{\mathrm{US}}$ & 7 & 24.4 & $7.1(1171.3)$ & $6.0(428.8)$ \\
\hline M2 & 6.3 & 37 & $0.2(1.5)$ & $4.9(138.9)$ \\
\hline $\mathrm{Wt}^{\mathrm{CA}}$ & 7 & 19.3 & $7.3(1502.3)$ & $6.3(589.6)$ \\
\hline Water & 1.4 & 52.8 & $-1.8(0.2)$ & $1.0(2.1)$ \\
\hline Contrasts: $\mathrm{Wt}^{\mathrm{CA}}$ vs. $\mathrm{Wt}^{\mathrm{US}}$ & $P=0.977$ & $P=0.022$ & $P=0.088$ & $P=0.174$ \\
\hline $\mathrm{M} 2$ vs. Wt ${ }^{\mathrm{US}}$ & $P<0.001$ & $P<0.001$ & $P<0.001$ & $P<0.001$ \\
\hline \multicolumn{5}{|l|}{ Maize inbred C0359 } \\
\hline $\mathrm{Wt}^{\mathrm{US}}$ & 7 & 22.1 & $7.0(1072.9)$ & $6.1(486.5)$ \\
\hline M2 & 6.9 & 29.6 & $0.7(2.2)$ & $5.7(307.5)$ \\
\hline $\mathrm{Wt}^{\mathrm{CA}}$ & 6.5 & 30.6 & $6.5(680.2)$ & $5.8(324.3)$ \\
\hline Water & 1.2 & 58.7 & $-1.8(0.2)$ & $1.2(2.6)$ \\
\hline Contrasts: $\mathrm{Wt}^{\mathrm{CA}}$ vs. $\mathrm{Wt}^{\mathrm{US}}$ & $P=0.008$ & $P<0.001$ & $P=0.003$ & $P=0.105$ \\
\hline $\mathrm{M} 2$ vs. $\mathrm{Wt}^{\mathrm{US}}$ & $P=0.617$ & $P=0.002$ & $P<0.001$ & $P=0.052$ \\
\hline $\mathrm{SED}^{\mathrm{d}}$ & 0.1 & 2 & 0.1 & 0.2 \\
\hline
\end{tabular}

${ }^{\text {a }} \mathrm{Wt}^{\mathrm{US}}$ is GZ3639 (TRI5 $\left.^{+}\right)$; $\mathrm{M} 2$ is GZT40 $\left(\right.$ TRI5 $\left.^{-}\right)$; $\mathrm{Wt}^{\mathrm{CA}}$ is DAOM180378.

${ }^{\mathrm{b}}$ Kernel weight.

${ }^{\mathrm{c}}$ Natural logarithm.

${ }^{\mathrm{d}}$ Standard error of the difference for comparing any two inoculation treatments within maize inbreds. 
means for ergosterol and fungal DNA quantitation from the Ontario silk channel inoculation experiment was high (0.86) (Fig. 3). Partial correlation of these means with design effects removed was $0.44(P=$ $0.006, n=48$ ). The PCR assay is specific to F. graminearum, while the ergosterol determination will quantify all fungi present.
However, visual disease assessment, ergosterol assays, and specific PCR detection in water-inoculated control plots indicated that little natural contamination was present at this site, making it possible to use both methods to quantify $F$. graminearum.

Illinois test site. The trichothecenenonproducing strains M1 and M2 caused
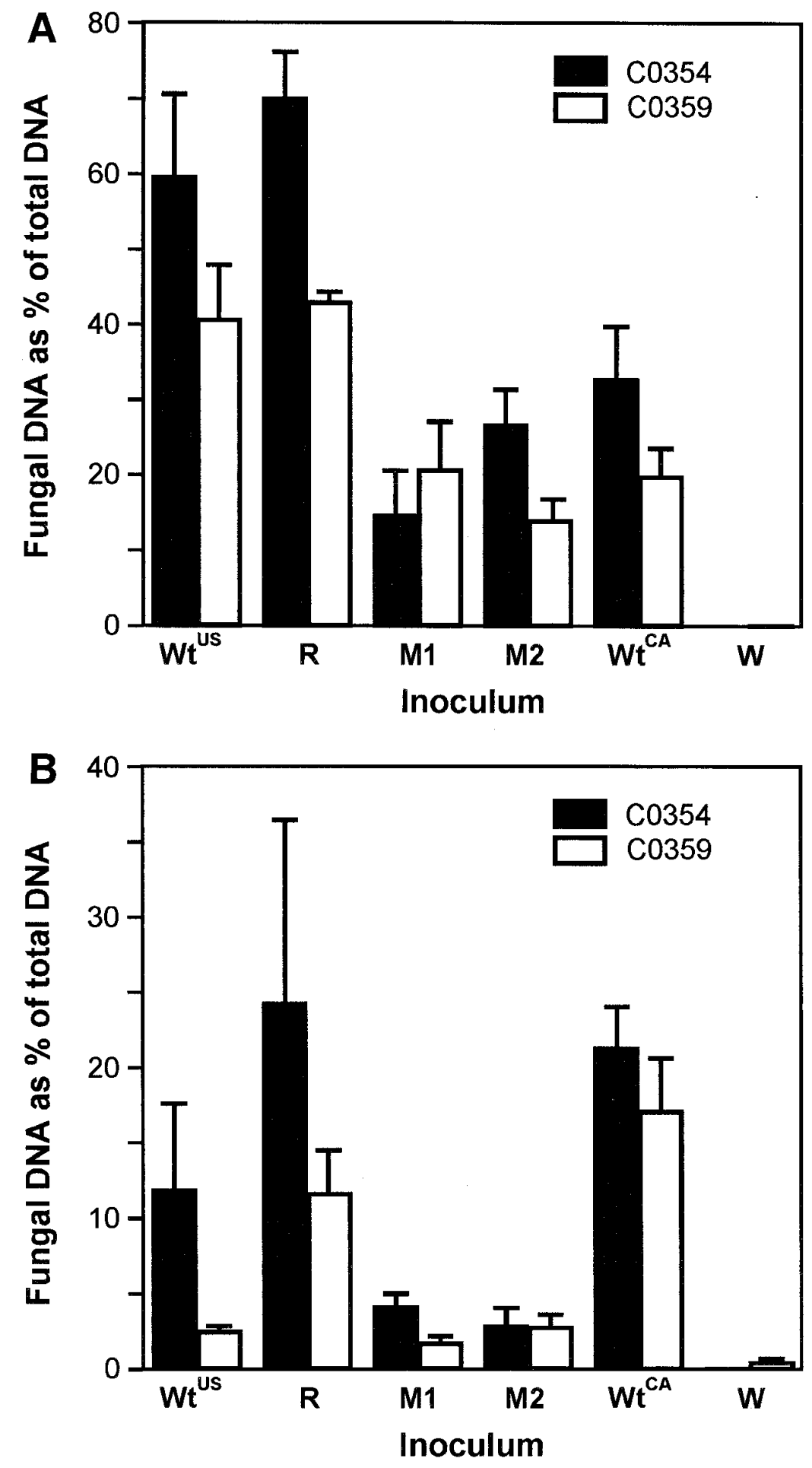

Fig. 2. Fungal DNA quantitation using polymerase chain reaction (PCR). Determination of fungal DNA as a percentage of total DNA in ground kernels of silk channel-inoculated ears. The inoculum treatments are $\mathrm{Wt}^{\mathrm{US}}=\mathrm{GZ3639}\left(\right.$ wild-type TRI $\left.^{+}\right), \mathrm{R}=\mathrm{GZT} 106\left(\right.$ revertant TRI5 ${ }^{+}$), $\mathrm{M} 1=\mathrm{GZT} 33$ $\left(T_{R I 5^{-}}\right), \mathrm{M} 2=\operatorname{GZT} 40\left(\right.$ TRI5 $\left.^{-}\right), \mathrm{Wt}^{\mathrm{CA}}=\mathrm{DAOM} 180378$ (wild-type TRI $\left.^{+}\right)$, and $\mathrm{W}=$ water. Error bars represent the standard error of the individual mean. (A) Ontario test site; (B) Illinois test site.

significantly less visual disease than $\mathrm{Wt}^{\mathrm{US}}$ and $\mathrm{R}$ on inbred $\mathrm{CO} 359(P=0.024)$ (Table $3)$. However, there were no significant differences in mean disease ratings between producing and nonproducing strains when inoculated on inbred CO354. Nevertheless, inoculation with the trichothecene-producing strains resulted in a higher proportion of severely diseased ears (75 to $100 \%$ symptomatic kernels, disease rating of 7) than did inoculation with the trichothecene-nonproducing strains (Fig. 1C and D). There was also a high proportion of ears with low levels of disease severity (1 to $25 \%$ symptomatic kernels, disease rating 2 to 4) following inoculation with all Fusarium strains. This variability becomes evident in Figure 1C and D, where one can see the bimodal nature of the visual disease frequency distribution of $\mathrm{Wt}^{\mathrm{US}}$ - and $\mathrm{R}$ inoculated ears. The water-inoculated CO359 ears had a mean disease rating of 3.4 , due mainly to contamination of ear tips with smut (Ustilago maydis), which may have contributed to the overall ear rot rating. Fumonisin analysis of grain from water-inoculated $\mathrm{CO} 359$ ears from the Illinois site (data not shown) demonstrated that there were low levels of fumonisin (1.45 to $8.92 \mu \mathrm{g} / \mathrm{g}$ of combined FB1, FB2, and FB3) and, presumably, $F$. verticillioides (formerly $F$. moniliforme) contamination.

At the Illinois test site, there were no significant effects on yield among the different $F$. graminearum inocula (Table 3 ). This was probably due to the high variation in disease observed within treatments.

GC/MS was used to determine DON concentrations in the kernels from Illinois. Kernels from ears inoculated with trichothecene-producing strains had mean DON concentrations ranging from 75.9 to 370.5 ppm, while kernels from ears inoculated with nonproducing strains had DON levels of 0.1 to 3.5 ppm (Table 3).

Other than DON quantitation, the analysis which yielded the most significant differences $(\mathrm{P} \leq 0.01)$ between trichotheceneproducing and -nonproducing strains at the Illinois site was quantitative PCR (Fig. 2B). Inoculation of $\mathrm{CO} 354$ ears with strains $\mathrm{Wt}^{\mathrm{US}}$ and $\mathrm{R}$ resulted in 11.7 and $24.0 \%$, respectively, $F$. graminearum DNA relative to total DNA, while inoculation with strains M1 and M2 resulted in 4.2 and $2.9 \%$, respectively, $F$. graminearum DNA (Fig. 2B). However, although CO359 ears contained $11.6 \% \quad F$. graminearum DNA when inoculated with the revertant $\mathrm{R}$ strain, ears inoculated with $\mathrm{Wt}^{\mathrm{US}}(2.4 \%$ Fusarium DNA) did not contain a higher proportion of fungal DNA than did the nonproducing strains (1.7 and 2.8\%) (Fig. 2B). This is not surprising in light of the high number of ears with visual disease ratings of 2 or 3 when inoculated with $\mathrm{Wt}^{\mathrm{US}}$. The specificity of the PCR assay enabled the quantitation of $F$. graminearum in the Illinois seed, even in the presence of 
such contaminating fungi as $F$. verticillioides and $U$. maydis.

Detection of Fusarium isolates. There was little evidence of natural background $F$. graminearum infection at either field site. F. graminearum was not recovered from kernels from randomly sampled border row ears or from ears inoculated with water only, as assayed by plating on selective media and PCR analysis (data not shown). PCR analysis of isolates from kernels from all treatment groups also indicated that there was little or no contamination by background $F$. graminearum infection and little or no cross-contamination of inoculated strains, and reinforced the conclusion that the trichothecene-nonproducing strains M1 and M2 were able to cause a reduced level of ear rot symptoms.

\section{DISCUSSION}

In animal and yeast cell culture studies, the major biological activity of the trichothecenes is inhibition of protein synthesis (8). DON has been shown to inhibit protein synthesis in isolated wheat polysomes (15). Trichothecenes apparently are not essential for fungal growth in vitro, because field strains and mutants that do not produce trichothecenes grow as vigorously as trichothecene-producing strains in the laboratory (10). Some studies have suggested that trichothecenes may be translocated in the plant tissues in advance of fungal growth $(29,35)$. As trichothecenes probably act to impair protein synthesis in plants, trichothecenes could suppress or delay the plant defense response against a fungal attack.

The results from this field trial lead us to the conclusion that trichothecene production is not essential for $F$. graminearum to infect maize tissues. Trichothecene-nonproducing strains of $F$. graminearum were able to colonize maize ears but were usually less virulent than the trichotheceneproducing strains. Comparable results were obtained when these transgenic and wildtype strains were tested in wheat field trials (6). At the Ontario test site, the trichothecene-nonproducing $\mathrm{M} 1$ and M2 strains were significantly less virulent than the trichothecene-producing $\mathrm{Wt}^{\mathrm{US}}$ and $\mathrm{R}$ strains when inoculated through the silk channel for all parameters tested. When kernel inoculation was utilized, M2 was significantly less virulent than $\mathrm{Wt}^{\mathrm{US}}$ on inbred CO354, but only yield and DON measurements yielded significant differences on inbred CO359. Compared with Ontario, there was much greater variation within treatments in Illinois (Table 3). Temperature and humidity have a strong influence on Gibberella ear rot, and the hotter, drier conditions in Illinois may not have been as conducive for disease development as the cooler, wetter conditions in Ontario. In Illinois, the M1 and M2 strains produced significantly less visual disease than the $\mathrm{Wt}^{\mathrm{US}}$ and $\mathrm{R}$ strains on inbred
CO359, but not on inbred CO354. Quantitative PCR (measuring $F$. graminearum DNA relative to total DNA) revealed significantly more fungal growth of trichothecene-producing versus -nonproducing strains on CO354, but not on CO359. Thus, the decreased virulence of strains unable to produce trichothecenes was apparent at the Ontario site, but this observation was less clear at the Illinois site due to the wider variation in disease development. This implies that trichothecenes such as DON may have similar roles in the virulence of $F$. graminearum on wheat head blight and Gibberella ear rot of maize.
Due to the requirement to minimize the potential escape of transgenic fungi from the field trial boundaries, these trials were harvested earlier than typical $F$. graminearum inoculation experiments (5 to 7 weeks versus 12 to 14 weeks). However, Reid and Sinha (24) found that disease symptoms on hybrid maize usually stabilized by 6 weeks postinoculation. Miller et al. (16) had also observed that, after toothpick inoculation of ears, the number of $F$. graminearum $\mathrm{CFU}$ increased until 6 weeks after inoculation, whereupon levels began to decline. Therefore, we would not expect that there would have been further signifi-

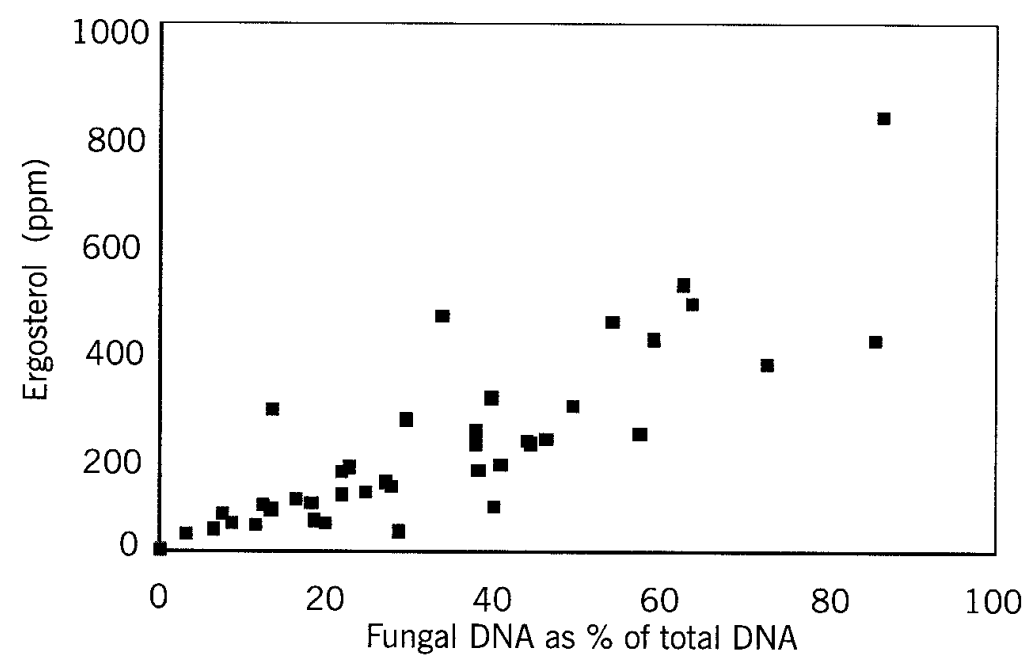

Fig. 3. Correlation of two fungal load quantitation methods. Mean ergosterol concentration in ppm versus mean fungal DNA as a percentage of total DNA from the Ontario silk channel inoculation experiment.

Table 3. Mean values of disease rating, yield, and deoxynivalenol (DON) content for silk channelinoculated maize ears in Illinois

\begin{tabular}{|c|c|c|c|}
\hline Inoculation $^{\mathrm{a}}$ & Disease rating & Yield kwt/ear (g) & $\begin{array}{c}\mathbf{L n}^{\mathrm{c}}(\mathrm{DON}+1) \\
(\mathrm{DON} \text { in ppm) }\end{array}$ \\
\hline \multicolumn{4}{|l|}{ Maize inbred C0354 } \\
\hline $\mathrm{Wt}^{\mathrm{US}}$ & 4.8 & 60 & $5.1(179.5)$ \\
\hline $\mathrm{R}$ & 4.8 & 53.1 & $5.6(370.5)$ \\
\hline M1 & 4.2 & 59.9 & $0.3(0.9)$ \\
\hline M2 & 4.7 & 64.5 & $0.1(0.1)$ \\
\hline $\mathrm{Wt}^{\mathrm{CA}}$ & 5.4 & 44.2 & $5.7(315.7)$ \\
\hline Water & 1.5 & 76.6 & $0.0(0.0)$ \\
\hline $\mathrm{SED}^{\mathrm{d}}$ & 0.3 & 5.5 & 0.4 \\
\hline Contrasts: $\mathrm{R}$ vs. $\mathrm{Wt}^{\mathrm{US}}$ & $P=0.994$ & $P=0.227$ & $P=0.212$ \\
\hline M1 vs. M2 & $P=0.127$ & $P=0.411$ & $P=0.538$ \\
\hline $\mathrm{R} \& \mathrm{Wt} \mathrm{U}^{\mathrm{US}}$ vs. M's & $P=0.209$ & $P=0.163$ & $P<0.001$ \\
\hline \multicolumn{4}{|l|}{ Maize inbred CO359 } \\
\hline $\mathrm{Wt}^{\mathrm{US}}$ & 4.6 & 63.5 & $4.2(75.9)$ \\
\hline $\mathrm{R}$ & 4.5 & 57 & $4.3(127.2)$ \\
\hline M1 & 4.2 & 67.3 & $0.3(1.1)$ \\
\hline M2 & 3.9 & 63.2 & $1.3(3.5)$ \\
\hline $\mathrm{Wt}^{\mathrm{CA}}$ & 4.8 & 58.1 & $4.9(160.1)$ \\
\hline Water & 3.4 & 69.8 & $0.0(0.0)$ \\
\hline $\mathrm{SED}^{\mathrm{e}}$ & 0.3 & 4.1 & 0.3 \\
\hline Contrasts: $\mathrm{R}$ vs. $\mathrm{Wt}^{\mathrm{US}}$ & $P=0.810$ & $P=0.138$ & $P=0.665$ \\
\hline M1 vs. M2 & $P=0.268$ & $P=0.343$ & $P=0.007$ \\
\hline$R \& W t^{U S}$ vs. M's & $P=0.024$ & $P=0.104$ & $P<0.001$ \\
\hline
\end{tabular}

${ }^{a} \mathrm{Wt}^{\mathrm{US}}$ is GZ3639 $\left(\right.$ TRI5 $\left.^{+}\right)$; $\mathrm{R}$ is GZT106 (TRI5 $\left.{ }^{+}\right)$; M1 is GZT33 (TRI5-); M2 is GZT40 (TRI5-); $\mathrm{Wt}^{\mathrm{CA}}$ is DAOM180378.

${ }^{b}$ Kernel weight.

c Natural logarithm.

${ }^{\mathrm{d}}$ Standard error of the difference for comparing any two inoculation treatments for CO354.

${ }^{\mathrm{e}}$ Standard error of the difference for comparing any two inoculation treatments for CO359. 
cant disease development beyond 6 weeks after silking.

Following the trend observed in visual disease symptoms and yield, the wild-type $\mathrm{Wt}^{\mathrm{US}}$ strain produced much higher levels of DON at the Ontario site than at the Illinois site (Tables 1 and 3) (e.g., in CO354 ears, 1,302.1 ppm in Ontario versus 179.5 ppm in Illinois). In contrast, the wild-type $\mathrm{Wt}^{\mathrm{CA}}$ strain produced very similar DON concentrations at the two sites (Tables 1 and 3) (e.g., in CO354 ears, 484.8 ppm in Ontario versus $315.7 \mathrm{ppm}$ in Illinois). Using the same Canadian wild-type isolate, $\mathrm{Wt}^{\mathrm{CA}}$, Reid and Sinha (24) determined DON concentrations in 10 hybrids in 1993 and 1994 using the CD-ELISA method. Hybrid lines from the 1993 experiment that exhibited similar disease severity ratings as inbreds CO354 and CO359 in this study also accumulated similar levels of DON compared with the inbred ears (Tables 1 and $3 ; 24)$.

In addition to trichothecenes, $F$. graminearum produces a wide variety of metabolites, including zearalenone and fusarins, and any number of these may also contribute to plant pathogenesis. The molecular approach of producing fungal gene disruption mutants has allowed us to tentatively identify trichothecenes as the first significant virulence factor in Gibberella ear rot. This approach can lead to the recognition of other mechanisms the fungi may use to attack plants.

\section{ACKNOWLEDGMENTS}

We thank R. Sinha and S. M. Poling for DON quantitation and Carmen Gervais, Sharon Allard, Marcie Moore, and Roopa Krishna for technical assistance. This research was partially supported by the Ontario Corn Producers' Association. P. Nicholson and G. Weston would like to thank the Ministry of Agriculture Fisheries and Food for support.

\section{LITERATURE CITED}

1. Bennett, G. A., Wicklow, D. T., Caldwell, R. W., and Smalley, E. B. 1988. Distribution of trichothecenes and zearalenone in Fusarium graminearum: Rotted corn ears grown in a controlled environment. J. Agric. Food Chem. 36:639-642.

2. Bowden, R. L., and Leslie, J. F. 1992. Nitratenonutilizing mutants of Gibberella zeae (Fusarium graminearum) and their use in determining vegetative compatibility. Exp. Mycol. 16:308-315.

3. Desjardins, A. E., Christ-Harned, E. A., McCormick, S. P., and Secor, G. A. 1993. Population structure and genetic analysis of field resistance to thiabendazole in Gibberella pulicaris from potato tubers. Phytopathology 83:164-170.

4. Desjardins, A. E., and Hohn, T. M. 1997. Mycotoxins in plant pathogenesis. Mol. Plant-
Microbe Interact. 10:147-152.

5. Desjardins, A. E., Hohn, T. M., and McCormick, S. P. 1992. Effect of gene disruption of trichodiene synthase on the virulence of Gibberella pulicaris. Mol. Plant-Microbe Interact. 5:214-222.

6. Desjardins, A. E., Proctor, R. H., Bai, G., McCormick, S. P., Shaner, G., Buechley, G., and Hohn, T. M. 1996. Reduced virulence of trichothecene-nonproducing mutants of Gibberella zeae in wheat field tests. Mol. PlantMicrobe Interact. 9:775-781.

7. Farber, J. M., and Sanders, G. W. 1986. Production of fusarin C by Fusarium spp. J. Agric. Food Chem. 34:963-966.

8. Feinberg, B., and McLaughlin, C. S. 1989. Biochemical mechanism of action of trichothecene mycotoxins. Page 27 in: Trichothecene Mycotoxicosis: Pathophysiologic Effects. V. R. Beasley, ed. CRC Press, Boca Raton, FL.

9. Hohn, T. M., and Beremand, P. D. 1989. Isolation and nucleotide sequence of a sesquiterpene cyclase gene from the trichothecene-producing fungus Fusarium sporotrichioides. Gene 79:131-138.

10. Hohn, T. M., and Desjardins, A. E. 1992. Isolation and gene disruption of the Tox5 gene encoding trichodiene synthase in Gibberella pulicaris. Mol. Plant-Microbe Interact. 5:249256.

11. Hohn, T. M., and Van Middlesworth, F. 1986. Purification and characterization of the sesquiterpene cyclase trichodiene synthetase from Fusarium sporotrichioides. Arch. Biochem. Biophys. 251:756-761.

12. Hopwood, A., Oldroyd, N., Fellows, S., Ward, R., Owen, S. A., and Sullivan, K. 1997. Rapid quantification of DNA samples extracted from buccal scrapes prior to DNA profiling. Biotechniques 23:18-20.

13. Marasas, W. F. O., Nelson, P. E., and Toussoun, T. A. 1984. Toxigenic Fusarium Species: Identity and Mycotoxicology. Pennsylvania State University, University Park. pp. 155-211.

14. McMullen, M., Jones, R., and Gallenberg, D. 1997. Scab of wheat and barley: A re-emerging disease of devastating impact. Plant Dis. 81:1340-1348.

15. Miller, J. D., and Ewen, M. A. 1997. Toxic effects of deoxynivalenol on ribosomes and tissues of the spring wheat cultivars Frontana and Casavant. Nat. Toxins 5:234-237.

16. Miller, J. D., Young, J. C., and Trenholm, H. L. 1983. Fusarium toxins in field corn. I. Time course of fungal growth and production of deoxynivalenol and other mycotoxins. Can. J. Bot. 61:3080-3087.

17. Mirocha, C. J., and Christensen, C. M. 1974. Fungus metabolites toxic to animals. Annu. Rev. Phytopathol. 12:303-330.

18. Nelson, P. E., Toussoun, T. A., and Marasas, W. F. O. 1983. Fusarium Species: An Illustrated Manual for Identification. Pennsylvania State University, University Park.

19. Nicholson P., Simpson, D. R., Weston, G., Rezanoor, H. N., Lees, A. K., Parry, D. W., and Joyce, D. 1998. Detection and quantification of Fusarium culmorum and Fusarium graminearum in cereals using PCR assays. Phys. Mol. Plant Pathol. 53:17-38.

20. Proctor, R. H., Hohn, T. M., and McCormick,
S. P. 1995. Reduced virulence of Gibberella zeae caused by disruption of a trichothecene toxin biosynthetic gene. Mol. Plant-Microbe Interact. 8:593-601.

21. Reid, L. M., Hamilton, R. I., and Mather, D. E. 1996. Screening maize for resistance to Gibberella ear rot. Tech. Bull. 1996-5E, Agriculture \& Agri-food Canada, Ottawa, Ontario. pp. 1-40.

22. Reid, L. M., Hamilton, R. I., and Schaafsma, A. W. 1997. Automatic pipettor for inoculation of maize kernels for evaluation of resistance to Fusarium graminearum. Can. J. Plant Pathol. 19:185-187.

23. Reid, L. M., Mather, D. E., Hamilton, R. I., and Bolton, A. T. 1992. Genotypic differences in the resistance of maize silk to Fusarium graminearum. Can. J. Plant Pathol. 14:211214.

24. Reid, L. M., and Sinha, R. C. 1998. Maize maturity and the development of gibberella ear rot symptoms and deoxynivalenol after inoculation. Eur. J. Plant Pathol. 104:147-154.

25. Sharma, R. P., and Kim, Y.-W. 1991. Trichothecenes. Page 339 in: Mycotoxins and Phytoalexins. R. P. Sharma and D. K. Salunkhe, eds. CRC Press, Boca Raton, FL.

26. Sinha, R. C., and Savard, M. E. 1996. Comparison of immunoassay and gas chromatography methods for the detection of the mycotoxin deoxynivalenol in grain samples. Can. J. Plant Pathol. 18:233-236.

27. Sinha, R. C., and Savard, M. E. 1997. Concentration of deoxynivalenol in single kernels and various tissues of wheat heads. Can. J. Plant Pathol. 19:8-12.

28. Snedecor, G. W., and Cochran, W. G. 1980. Statistical Methods. 7th ed. Iowa State University, Ames.

29. Snijders, C. H. A., and Krechting, C. F. 1992. Inhibition of deoxynivalenol translocation and fungal colonization in Fusarium head blight resistant wheat. Can. J. Bot. 70:1570 1576.

30. Sutton, J. C. 1982. Epidemiology of wheat head blight and maize ear rot caused by Fusarium graminearum. Can. J. Plant Pathol. 4:195-209.

31. Sutton, J. C., Baliko, W., and Liu, H. J. 1980. Fungal colonization and zearalenone accumulation in maize ears injured by birds. Can. J. Plant. Sci. 60:453-461.

32. Tuite, J. 1969. Plant Pathological Methods: Fungi and Bacteria. Burgess Publishing Co., Minneapolis, MN.

33. Van Egmond, H. P. 1989. Current situation on regulation for mycotoxins. Overview of tolerances and status of standard methods of sampling and analysis. Food Addit. Contam. 6:139-188.

34. Young, J. C. 1995. Microwave-assisted extraction of the fungal metabolite ergosterol and total fatty acids. J. Agric. Food Chem 43:2904-2910.

35. Young, J. C., and Miller, J. D. 1985. Appearance of fungus, ergosterol and Fusarium mycotoxins in the husk, axial stem and stalk after ear inoculation of field corn. Can. J. Plant Sci. 65:47-53.

36. Zamir, L. O., Gauthier, M. J., Devor, K. A., Nadeau, Y., and Sauriol, F. 1989. Trichodiene is a precursor to trichothecenes. J. Chem. Soc. Chem. Comm. 1989:598-600. 